\title{
$\begin{array}{ll}\text { Research Square } & \begin{array}{l}\text { Preprints are preliminary reports that have not undergone peer review. } \\ \text { They should not be considered conclusive, used to inform clinical practice, } \\ \text { or referenced by the media as validated information. }\end{array}\end{array}$
}

\section{Antibacterial and Antibiofilm Effects Extracts From Elaeagnus Angustifolia,satureja Montana, Quercus Brantii, Tragopogon Dubius, Sonchus Asper, on the P.aeruginosa and S.aureus}

\author{
Razieh Sadat Hosseini \\ Shahrekord University of Medical Sciences \\ Mansoor khaledi \\ Shahed University \\ Abolfazl Gholipour ( $\square$ gholipoa@gmail.com ) \\ Shahrekord University of Medical Sciences
}

\section{Research Article}

Keywords: Antibacterial, Antibiofilm, P.aeruginosa, S.aureus, Elaeagnus angustifolia, satureja montana,

Posted Date: December 30th, 2020

DOI: https://doi.org/10.21203/rs.3.rs-128497/v1

License: @ (i) This work is licensed under a Creative Commons Attribution 4.0 International License. Read Full License 


\section{Abstract}

Background: Due to the increase in microbial resistance worldwide and the adverse effects of chemical drugs, the study of antimicrobial compounds in plant extracts as a new source of medicine can be effective in reducing or solving this problem. The purpose of this study antibacterial and antibiofilm effects extracts from Elaeagnus angustifolia,satureja montana, Quercus brantii,Tragopogon dubius,Sonchus asper, on the P.aeruginosa and S.aureus

Methods: In this cross-sectional descriptive-analytical study, the study population is plants collected in Isfahan and Shahrekord and Pseudomonas and S.aureus bacteria isolated from clinical samples and standard strains. The sampling method was improbably simple and $120 \mathrm{~g}$ was collected from each of the 9 plants and extracted by massage method. For the qualitative evaluation of antimicrobial properties, you used the agar well diffusion method and for quantitative evaluation of antimicrobial properties, you used the plate microtiter method. To evaluate the anti-biofilm properties, plate microtiter method, and staining by violet crystal were used.

Results: Based on the findings of this study and the study of MBC and MIC of the mentioned plant extracts, it can be said that the best antibacterial effect on all studied strains belongs to the plant extracts of Quercus brantii, Elaeagnus angustifolia, satureja montana, Tragopogon dubius, and Sonchus asper, respectively. Among them, Quercus brantii extract has the best effect on all 4 strains. Also, in the study of anti-biofilm properties, it was observed that the Quercus brantii, satureja montana, and Elaeagnus angustifolia plant extracts had an anti-biofilm effect. Among them, respectively, the most belonging to the Quercus brantii, and the two extracts of Tragopogon dubius, and Sonchus asper do not have good anti-biofilm properties.

Conclusions: According to the results of this study on the antimicrobial and antifouling properties of these extracts, it is possible to use this plant in the future with more studies and more work on these plants.

\section{Background}

According to the latest WHO reports in 2018 from the data of the Organization for the monitoring of Antibiotic Resistance, shows a high level of resistance to some serious bacterial infections in low-income and low-income countries. The Global Antimicrobial Surveillance System (GLASS) shows that antibiotic resistance is widespread among 500,000 people with recurrent bacterial infections in 22 countries [1]. This global threat is increasing and our ability to treat nosocomial or community-acquired infections is declining. Excessive increase in antibiotic use can cause infectious diseases caused by multidrug-resistant microorganisms Therefore, to solve this challenge, identification and study of antimicrobial compounds in medicinal plant extracts as a new source of medicine and an alternative method can be effective [2-4]. The experience of the last few decades has shown that chemical drugs, with all their effectiveness, have many side effects and there is less pure substance that does not have adverse effects. In contrast, the active ingredients in medicinal plants have a state of biological equilibrium due to their association with other substances. Therefore, they do not accumulate in the body and do not cause side effects, and therefore have a significant advantage over chemical drugs [5]. On the other hand, we are facing an increase in treatment-resistant microbial strains, which necessitates the need for new antibiotics. Side effects and drug resistance to chemical drugs, as well as the discovery of new substances such as vitamins, hormones, antimicrobials, antivirals, and antitumors among newly discovered plants, have led to a resurgence in the use of drugs and products. Natural plants should be created and medicinal plants should be a good source for finding different drugs with fewer side effects [6]. Pseudomonas aeruginosa is an important and opportunistic gram-negative pathogen that can cause a variety of clinical infections, including wound and urinary tract infections and circulatory infections, especially in hospitalized and immunocompromised patients. It is the second leading cause of nosocomial pneumonia in the United States and the fifth leading cause of nosocomial urinary tract infections in Europe [7]. Pseudomonas aeruginosa is resistant to many disinfectants and antibiotics, including anti-Pseudomonas penicillins, ceftazidime, carbapenems, and ciprofloxacin [8]. Pseudomonas aeruginosa has many pathogens that are involved in acute infection. Alginate biofilm formation is one of the most significant mechanisms contributing to antibiotic resistance in Pseudomonas aeruginosa [9]. Staphylococcus aureus is gram-positive and optional anaerobic cocci. Staphylococcus aureus can cause a wide range of infections, from simple skin infections (such as boils, boils, scabs, eyelashes, and abscesses) to life-threatening diseases (such as pneumonia, meningitis, osteomyelitis, endocarditis, toxic shock syndrome, and sepsis). Staphylococcus aureus is one of the five most common causes of nosocomial infections, especially post-surgical wound infections. Each year, 500,000 people in US hospitals become infected with Staphylococcus aureus [10-12]. One of the pathogenic factors of this bacterium is the formation of biofilm, the ability of Staphylococcus aureus to bind and form a biofilm is a determining step in the chronicity of the disease [13]. Methicillin-resistant Staphylococcus aureus (MRSA) is a specific strain of the bacterium that is resistant to most antibiotics. MRSA is more common in hospitals but also acquired in the community [14] this study aimed to investigate the methanolic extract of several plants to evaluate the antimicrobial and antibiofilm properties against two drugs resistant to Pseudomonas aeruginosa and Staphylococcus aureus. The studied plants include (Elaeagnus angustifolia), (satureja montana), (Quercus.brantii), (Tragopogon dubius), (Sonchus asper), the last two of which are weeds. 


\section{Methods}

In this cross-sectional descriptive-analytical study, the studied population is plants collected in Isfahan and Shahrekord and Pseudomonas and Staphylococcus aureus bacteria isolated from clinical samples and standard strains. Plants collected by botanists were approved and other similar plants were excluded from the study. The sampling method was improbably simple and $120 \mathrm{~g}$ was collected and extracted from each of the 9 plants. Microbial strains did not require sampling and were prepared as lyophilized ampoules from Hajar Teaching Hospital in Shahrekord and Department of Microbiology, Shahrekord University of Medical Sciences. The volume of the tested sample was 486 . The validity of the plants collected was based on the information of local people familiar with the plants of the region and The plants were identified as the plants of interest by a botanist and pharmacognosist (Dr. zahra lorigooini) at the medical plant research center

of Shahrekord University of Medical Sciences. And were registered in the herbarium. Herbarium codes plants included: (satureja montana:208), (Elaeagnus angustifolia:1024), (Quercus.brantii:1025), (Sonchus asper.1026), (Tragopogon dubius:1027).

Data reliability was performed by repeating the above steps. Data were obtained based on the experiments mentioned in the implementation method.

\section{Preparation of plant extracts}

Plants of gardens and pastures around the city of Isfahan / Shahrekord with the help of natives and farmers familiar with the plants were collected and approved by a pharmacologist of the University of Medical Sciences and a botanist of the University of Isfahan. The methanolic extract of plants was prepared by Masirasson method and the resulting powder was stored in -20 freezer. Before each microbial test, the desired amount was extracted to prepare the appropriate concentration of powder and dissolved in $20 \%$ DMSO and then filtered by a 0.45 micron needle filter.

\section{Determination of antibacterial properties}

The desired clinical bacterial strains were prepared from two bacteria P.aeruginosa, S. aureus from each of the two microbially resistant strains by microbial collection from the laboratory of Hajar Teaching Hospital in Shahrekord. And again antibiotic pattern tests were performed on it and confirmed And two standard strains of each bacterium, with a specific antibiogram pattern according to CLSI2018 standard, were prepared, cultured, and activated in blood agar medium and again for microbial identification tests [15]. To evaluate the antibacterial properties of the extracts, qualitative concentrations of 100,70,50,30,10 (mg / ml) were prepared from each of the extracts using the formula M1V1 = M2V2. It was performed by the Nathan Agar Well Diffusion method and all plates were incubated at $37^{\circ} \mathrm{C}$ for 24 hours and the next day the diameter of the growth inhibition zone was measured with a ruler [16]. The Microdilution broth method was used to determine the MIC in plate 96 of sterile cells [17]. After 24 hours of incubation at $37^{\circ} \mathrm{C}$, the bottom of the plate was examined under light and the presence or absence of turbidity indicated the growth or non-growth of bacteria was noted in the special table. Due to the color of the extracts to ensure before and after incubation, the light absorption plate of the wells was read at $O D=260 \mathrm{~nm}$. By comparing the light absorption before and after incubation, the concentration that had changed significantly was selected as MIC to ensure 100 Landa of the contents of all wells in Müller Hinton agar and the concentration that prevented the growth of $99.9 \%$ of bacteria. The title MBC and the well before that were chosen as MIC. The initial stock of the extract was selected according to the results of agar well diffusion and made with the help of DMSO solvent and filtered with a 0.45 micron needle filter. The initial stock of the extract was selected according to the results of agar well diffusion and made with the help of DMSO solvent and filtered with a 0.45 micron needle filter. And was selected for the microtiter test It should be noted that the initial stock is a concentration higher than the concentration of the first well of this method.

\section{Determination of anti-biofilm properties}

To dilute the extracts of each plant in the formation of bacterial biofilm, the dilution method was used in the well. To do this, two dilutions before and after MIC were selected for this purpose. After the procedure and incubation for 24 hours, remove the contents of the wells and add sterile physiology serum Shake the microplate gently until the cells are separated by weak or free binding. Remove the contents of the wells again and add 300 microliters of $96 \%$ alcohol to the wells for 15 minutes to fix the cells After removing the alcohol, the wells were stained with $2 \%$ crystal violet dye for 5 minutes and after this time, the wells were washed and $33 \%$ acetic acid was added to them and set at $630 \mathrm{~nm}$ in ELISA reader. Contracted and then its OD is measured [18]. Then the extract biofilm reduction was investigated using the following formula.

Percentage of biofilm reduction $==\{((O D C-O D B)-(O D T-O D B)) \div(O D C-O D B)\} \times 100$

Optical absorption of positively controlled wells = ODC

Optical absorption of negatively controlled wells $=$ ODB 
The initial stock of the extract was selected based on the results of agar well diffusion It was made with the help of DMSO solvent and filtered with a needle filter of 0.45 microns. And for plate microtiter test was selected. It should be noted that the initial stock is a concentration higher than the concentration of the first well of this method.

\section{Results}

Qualitative method of determining the antibacterial property or the same as diffusion to qualitatively confirm the antibacterial properties of the extracts and find the approximate range of antibacterial properties of the extracts. The results showed that each plant had antibacterial properties to each extract and the appropriate concentration range for MIC was determined. It was found that all extracts in the tested concentrations of $100,70,50,30$, and $10(\mathrm{mg} / \mathrm{ml})$ have antimicrobial properties. And some extracts in the concentration range less than 10 also had this property. (as shown in Tables 1,2 )

In this study, MIC and MBC and anti-biofilm properties of Elaeagnus angustifolia,satureja montana, Quercus brantii,Tragopogon dubius,Sonchus asper plants for standard and resistant strains of P.aeruginosa, standard and resistant strains of S. aureus are as follows, Based on the findings of this study and the study of MBC and MIC of the mentioned plant extracts, it can be said that the best antibacterial effect on all studied strains belongs to the plant extracts of Quercus brantii, Elaeagnus angustifolia, satureja montana, Tragopogon dubius, and Sonchus asper, respectively. Among them, Quercus brantii extract has the best effect on all 4 strains. Also, in the study of anti-biofilm properties, it was observed that the Quercus brantii, satureja montana, and Elaeagnus angustifolia plant extracts had an anti-biofilm effect. Among them, respectively, the most belonging to the Quercus brantii, and the two extracts of Tragopogon dubius, and Sonchus asper do not have good anti-biofilm properties.

Table 1

MIC results of the studied plants on the studied bacteria in terms of $\mathrm{mg} / \mathrm{ml}$

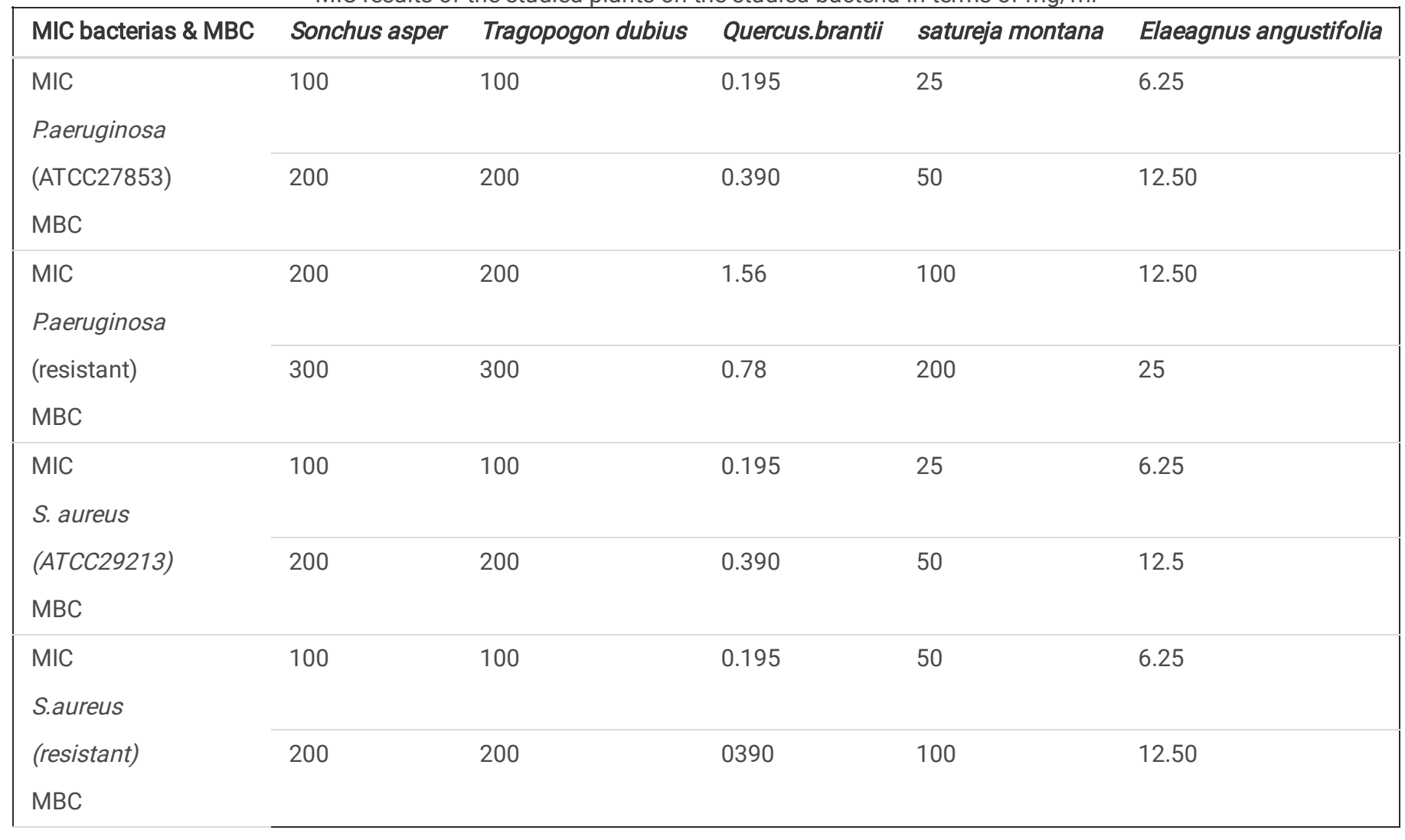

Table 2 Results of the reduction of biofilm production in different concentrations of the studied extracts on P.aeruginosa and S.aureus strains 


\begin{tabular}{|c|c|c|c|c|c|c|c|c|c|c|c|c|c|c|}
\hline \multirow[t]{2}{*}{ Extract type } & \multirow{2}{*}{$\begin{array}{l}\text { Bacterial } \\
\text { type }\end{array}$} & \multicolumn{13}{|c|}{ Extract concentration $(\mathrm{mg} / \mathrm{ml})$} \\
\hline & & 200 & 100 & 50 & 25 & 12.5 & 6.25 & 3.125 & 1.59 & 0.75 & 0.397 & 0.195 & 0.09 & 0.03 \\
\hline \multirow{6}{*}{$\begin{array}{l}\text { satureja } \\
\text { montana }\end{array}$} & Paeruginosa & 100 & 100 & 100 & 99 & 80 & 50 & - & - & - & - & - & - & - \\
\hline & (ATCC27853) & & & & & & & & & & & & & \\
\hline & Paeruginosa & 100 & 100 & 90 & 70 & 50 & 10 & - & - & - & - & - & - & - \\
\hline & (sensitive) & & & & & & & & & & & & & \\
\hline & S.aureus & 80 & 81 & 55 & 42 & 15 & 0 & - & - & - & - & - & - & - \\
\hline & (resistant) & & & & & & & & & & & & & \\
\hline \multirow{6}{*}{$\begin{array}{l}\text { Elaeagnus } \\
\text { angustifolia }\end{array}$} & P.aeruginosa & - & - & - & 100 & 100 & 98 & 74 & 88 & 50 & - & - & - & - \\
\hline & (ATCC27853) & & & & & & & & & & & & & \\
\hline & Paeruginosa & - & - & - & 100 & 100 & 90 & 80 & 70 & 42 & - & - & - & - \\
\hline & (sensitive) & & & & & & & & & & & & & \\
\hline & S.aureus & - & - & - & 100 & 100 & 88 & 70 & 57 & 34 & - & - & - & - \\
\hline & (resistant) & & & & & & & & & & & & & \\
\hline \multirow{6}{*}{ Quercus.brantii } & Paeruginosa & - & - & - & - & - & 100 & 100 & 100 & 100 & 98 & 70 & 50 & - \\
\hline & (ATCC27853) & & & & & & & & & & & & & \\
\hline & Paeruginosa & - & - & - & - & - & 100 & 100 & 100 & 99 & 82 & 72 & - & - \\
\hline & (sensitive) & & & & & & & & & & & & & \\
\hline & S.aureus & - & - & - & - & - & 100 & 100 & 100 & 98 & 90 & 87 & 57 & 0 \\
\hline & (resistant) & & & & & & & & & & & & & \\
\hline
\end{tabular}

\section{Discussion}

In this study, MIC and MBC and anti-biofilm properties of Elaeagnus angustifolia,satureja montana, Quercus brantii, Tragopogon dubius, Sonchus asper plants for standard and resistant strains of P.aeruginosa, standard and resistant strains of $S$. aureus are as follows, Based on the findings of this study and the study of MBC and MIC of the mentioned plant extracts, it can be said that the best antibacterial effect on all studied strains belongs to the plant extracts of Quercus brantii, Elaeagnus angustifolia, satureja montana, Tragopogon dubius, and Sonchus asper, respectively. Among them, Quercus brantii extract has the best effect on all 4 strains. Also, in the study of anti-biofilm properties, it was observed that the Quercus brantii, satureja montana, and Elaeagnus angustifolia plant extracts had an anti-biofilm effect. Among them, respectively, the most belonging to the Quercus brantii, and the two extracts of Tragopogon dubius, and Sonchus asper do not have good anti-biofilm properties.

The results of the study of Chusri et al (2012) showed that the extract of infectoria. Quercus is effective on methicillin-resistant Staphylococcus aureus biofilm formation [19] In a study by Hobby et al (2012), In relation to the effect of Quercus extract on the formation of Staphylococcus aureus biofilm, it was found that the Staphylococcus aureus was inhibited by Quercus extract [20]. Mohammadi et al (2015) In a study showed that Quercus extract strongly inhibited the formation of Streptococcus mutans biofilm at concentrations higher than $19.5 \mu \mathrm{g} / \mathrm{ml}$ [21]. This is in line with the results of the present study on the effect of Quercus extract on the formation of Staphylococcus aureus biofilm up to a concentration of $0.03 \mathrm{mg} / \mathrm{ml}$.

Sabir et al (2007) found that ether extract of Elaneagnu umbellate is effective against Escherichia coli bacteria Pseudomonas aeruginosa, Staphylococcus aureus, and Bacillus subtilis. And its aqueous extract can inhibit the growth of Escherichia coli and Staphylococcus aureus [22]. This study is in line with the present study and this study also showed that the methanolic extract of Elaneagnu against Pseudomonas aeruginosa, Staphylococcus aureus has anti-bacterial properties. In the study of Uysal et al (2018), the antibacterial, antifungal, and antioxidant abilities of T.dubius extract were investigated. Their results showed that this extract has antibacterial effects due to its phenolic compounds [23], which is in line with the present study and the results of this study also showed that T.dubius extract has antibacterial properties against Pseudomonas aeruginosa, Staphylococcus aureus. 
In the study of Shahbazi et al (2017), the antimicrobial activity of several plants was investigated, among which Tragopogon extract of the Kermanshah region was proven to have antimicrobial properties [24]. This is in line with the present study and the results of this study also showed that Tragopogon extract has antibacterial properties against Pseudomonas aeruginosa, Staphylococcus aureus.

In the study of Talei et al. (2008), antimicrobial properties were not found for the native Tragopogon of Khorramabad studied by them [25]. Which is contrary to the results of the present study.

In the study of Borjian et al. (2016), the antibacterial effects of hydroalcoholic extract of Q. brantii fruit on Listeria monocytogenes and Enterococcus faecalis were studied in the laboratory. These two bacteria have a growth inhibitory effect [26]. The results of this study also showed that the extract of the Quercus has antibacterial properties against Pseudomonas aeruginosa, Staphylococcus aureus.

In the study of Omidi et al. (2016), the results showed that the methanolic extract of Quercus brantii ,Elaeagnus had antibacterial and antibiofilm effects against Pseudomonas aeruginosa [27].

The results of this study also showed that the extract of Quercus has antibacterial properties against Pseudomonas aeruginosa, Staphylococcus aureus.

In the study of Khan et al. (2016), the antibacterial and antifungal effects of Quercus against Escherichia coli, Pseudomonas aeruginosa, Staphylococcus were investigated.[28]

In the study of Jamehdor et al. (2014) the results showed that the aqueous extract of Hippophae.rhamnoides has the greatest effect on Pseudomonas aeruginosa [29]. This study contradicts the results of this study and this study showed that the highest antibacterial effect on the standard strain of Pseudomonas aeruginosa is Quercus extract and in the second degree is Elaeagnus extract.

In the study of Ateufack et al (2014), the antibacterial effect of $H$.asperagainst bacteria of the Enterobacteriaceae family was investigated and the results showed that $H$.asper leaves have antibacterial and antidiarrheal effects [30]. This is in line with the present study and the results of this study also showed that H.asper extract has antibacterial properties against Pseudomonas aeruginosa, Staphylococcus aureus.

Azaz et al (2002), investigated the antibacterial activity of 3 species of satureja in S. Coeralen, S.pilosa, and S. Boissieri against Staphylococcus aureus, Pseudomonas aeruginosa, Escherichia coli, and Salmonella typhimurium. The results of this study showed that satureja has antibacterial properties [31].

In 2011, Mahboubi et al(2011) studied the essential oil of Satureja hortensis. In this study, the activity of this species against the bacteria of Staphylococcus aureus, Pseudomonas aeruginosa, Escherichia coli Salmonella typhimurium was proved [32].

In Teimori et al(2009) studies, the results showed that Satureja against Staphylococcus aureus, Micrococcus luteus, Bacillus cereus, Bacillus subtlebis, Pseudomonas aeruginosa, Pseudomonas aeruginosa [33].

In Özkalp et al (2009)studies, the results showed that Satureja has an inhibitory effect on the bacteria of Streptococcus pneumoniae, Salmonella enteridis, Klebsiella pneumoniae, Escherichia coli, Pseudomonas aeruginosa, and S.mutans [34]. The results of these studies are in line with the results of the present study. In general, it can be said that the results of these studies are in line with the results of our study and confirm the inhibitory and lethal effect of extracts on Pseudomonas aeruginosa.

In general, it can be said that the results of these studies are in line with the results of our study and confirm the inhibitory and lethal effect of extracts of Elaeagnus angustifolia,satureja montana, Quercus brantii,Tragopogon dubius,Sonchus asper, on the P.aeruginosa and S.aureus.

Slight differences in MIC and MBC values obtained from this study with other studies are probably due to the use of different parts of the plant such as leaves, fruits, flowers, gums, differences in plant species, harvest time, plant type, and strain under investigation.

\section{Conclusions}

According to the results of this study, the methanolic extract of the medicinal plants of, Elaeagnus angustifolia,satureja montana, Quercus brantii,Tragopogon dubius,Sonchus asper in vitro, has the anti-bacterial on the P.aeruginosa and S.aureus. And three extracts of Elaeagnus angustifolia,satureja montana, Quercus brantii leaves reduce the formation of bacterial biofilm. And due to the fact that antibiotic resistance is increasing day by day and the formation of biofilm by Pseudomonas aeruginosa causes an increase in resistance to antibiotics. Probably with more studies and more work on these plants in the future can use these plants as a therapeutic supplement along with antibiotics.

\section{Declarations}




\section{Acknowledgments}

This study was financially supported by Student Research Committee of Shahrekord University of Medical Sciences with grant number 3023. The authors are grateful to Student Research Committee and the staffs of Cellular \& Molecular Research Center, Shahrekord University of Medical Sciences, and the authorities of Shahrekord Hajar Hospital for their valuable helps.

\section{Author contributions}

All authors contributed to the study conception and design. Material preparation, data collection and analysis were performed by RSH, MK, AG. The first draft of the manuscript was written by RSH and all authors commented on previous versions of the manuscript. All authors read and approved the final manuscript.

\section{Funding}

This study was financially supported by Student Research Committee of Shahrekord University of Medical Sciences with grant number 3023.

\section{Availability of data and materials}

The datasets used and/or analyzed during the current study available from the corresponding author on reasonable request.

\section{Ethics approval}

All procedures performed in studies involving human participants were in accordance with the ethical standards of national research committee and with the 1964 Helsinki Declaration and its later amendments or comparable ethical standards.

The study was approved by the Ethics Committee of Shahrekord University of Medical Sciences under code IR.SKUMS.REC.1398.016.

\section{Consent to participate}

Informed consent was obtained from all individual participants included in the study

\section{Consent for publication}

Not applicable.

\section{Competing interests}

The authors have declared that no competing interests exist. All authors have approved this manuscript.

\section{Author details}

1Student Research Committee, Shahrekord University of Medical Sciences, Shahrekord , Iran

2Department of Microbiology, Faculty of Medicine, Shahed University, Tehran, Iran

3Cellular and Molecular Research Center, Basic Health Sciences Institute, Shahrekord University of Medical Sciences, Shahrekord, Iran

\section{References}

1. Maksimović Z, Samardžić S: Herbal Medicinal Products in the Treatment of Osteoarthritis. In: Osteoarthritis Biomarkers and Treatments. edn.: IntechOpen; 2018.

2. Khaledi M, Khaledi F, Asadi-Samani M, Gholipour A, Kouhi AM: Phytochemical evaluation and antibacterial effects of Medicago sativa, Onosma sericeum, Parietaria judaica L., Phlomis persica and Echinophora platyloba DC. on Enterococcus faecalis. Biomedical Research and Therapy 2018, 5(1):1941-1951.

3. Asadi-Samani M, Khaledi M, Khaledi F, Samarghandian S, Gholipour A: Phytochemical Properties and Antibacterial Effects of Salvia multicaulis Vahl., Euphorbia microsciadia Boiss., and Reseda lutea on Staphylococcus aureus and Acinetobacter baumanii. Jundishapur Journal of Natural Pharmaceutical Products 2019.

4. Ulloa-Urizar G, Aguilar-Luis MA, De Lama-Odría MdC, Camarena-Lizarzaburu J, del Valle Mendoza J: Antibacterial activity of five Peruvian medicinal plants against Pseudomonas aeruginosa. Asian Pacific Journal of Tropical Biomedicine 2015, 5(11):928-931.

5. Velag J SG: The Medicinal Plants. Persian vol. 5, Sixth Ed edn: Naghsh Iran publication; 2005. 
6. A AB: Iranian Medicinal Plants Encyclopedia., vol. 64, First Ed. edn: Tehran. Arjmand Publication.; 2000.

7. Vaez H, Faghri J, Esfahani BN, Moghim S, Fazeli H, Sedighi M, Safaei HG: Antibiotic resistance patterns and genetic diversity in clinical isolates of Pseudomonas aeruginosa isolated from patients of a referral hospital, Isfahan, Iran. Jundishapur journal of microbiology $2015,8(8)$.

8. Shaikh S, Fatima J, Shakil S, Rizvi SMD, Kamal MA: Prevalence of multidrug resistant and extended spectrum beta-lactamase producing Pseudomonas aeruginosa in a tertiary care hospital. Saudi journal of biological sciences 2015, 22(1):62-64.

9. Khalifa $\mathrm{ABH}$, Moissenet $\mathrm{D}$, Thien $\mathrm{HV}$, Khedher $\mathrm{M}$ : Les facteurs de virulence de Pseudomonas aeruginosa: mécanismes et modes de régulations. In: Annales de biologie clinique: 2011; 2011: 393-403.

10. Oglesby-Sherrouse AG, Djapgne L, Nguyen AT, Vasil Al, Vasil ML: The complex interplay of iron, biofilm formation, and mucoidy affecting antimicrobial resistance of Pseudomonas aeruginosa. Pathogens and disease 2014, 70(3):307-320.

11. Kluytmans J, Van Belkum A, Verbrugh H: Nasal carriage of Staphylococcus aureus: epidemiology, underlying mechanisms, and associated risks. Clinical microbiology reviews 1997, 10(3):505-520.

12. Khaledi M, Asadi-Samani M, Mahmoodi-Kouhi A, Gholipour A: Antibacterial effect of the hydroalcoholic extracts of four Iranian medicinal plants on Staphylococcus aureus and Acinetobacter baumanii. International Journal of Pharmaceutical And Phytopharmacological Research 2017, 7(2):10-14.

13. Arciola CR, Campoccia D, Gamberini S, Baldassarri L, Montanaro L: Prevalence of cna fnbA and fnbB adhesin genes among Staphylococcus aureus isolates from orthopedic infections associated to different types of implant. FEMS microbiology letters 2005, 246(1):81-86.

14. Gurusamy KS, Koti R, Toon CD, Wilson P, Davidson BR: Antibiotic therapy for the treatment of methicillin-resistant Staphylococcus aureus (MRSA) infections in surgical wounds. Cochrane Database of Systematic Reviews 2013(8).

15. Clinical and Laboratory Standards Institute (CLSI). Reference method forZone Diameter and MIC Breakpoints for Pseudomonas aeruginosa and Staphylococcus spp

16. Wikler MA: Performance standards for antimicrobial susceptibility testing: Seventeenth informational supplement: Clinical and Laboratory Standards Institute; 2007.

17. De Wet P, Rode H, Sidler D, Lastovica A: Allicin: a possible answer to antibiotic resistant campylobacter diarrhoeal infection? Archives of disease in childhood 1999, 81(3):278-278.

18. SL K: Concepts in Antimicrobial Therapy. In: Mahon CR,Manoselis G. Textbook of Diagostic Microbiology. In., Second Ed. edn. Philadelphia.: W.B Saunders Company.; 2000.

19. Chusri S, Phatthalung PN, Voravuthikunchai S: Anti-biofilm activity of Quercus infectoria G. Olivier against methicillin-resistant Staphylococcus aureus. Letters in applied Microbiology 2012, 54(6):511-517.

20. Hobby GH, Quave CL, Nelson K, Compadre CM, Beenken KE, Smeltzer MS: Quercus cerris extracts limit Staphylococcus aureus biofilm formation. Journal of ethnopharmacology 2012, 144(3):812-815.

21. Mohammadi-Sichani M, Karbasizadeh V, Chaharmiri Dokhaharani S: Effect of oak galls extracts on streptococcus mutans growth and biofilm formation. Journal of Mazandaran University of Medical Sciences 2015, 24(121):161-171.

22. Sabir MS, Ahmad DS, Imtiaz H, Tahir KM: Antibacterial activity of Elaeagnus umbellata (Thunb.) a medicinal plant from Pakistan. Saudi medical journal 2007, 28(2):259.

23. Uysal S, Senkardes I, Mollica A, Zengin G, Bulut G, Dogan A, Glamočlija J, Soković M, Lobine D, Mahomoodally FM: Biologically active compounds from two members of the Asteraceae family: Tragopogon dubius Scop. and Tussilago farfara L. Journal of Biomolecular Structure and Dynamics 2018.

24. Shahbazi Y: Antibacterial and Antioxidant Properties of Methanolic Extracts of Some Native Edible Plants Collected from Kermanshah, Western Iran. Journal of food quality and hazards control 2017, 4(4):93-98.

25. Talei G MMH, Mosav Z.: Antibacterial activity four medicinal plants of Lorestan, Iran. J Guilan Univ M 2007; 1((10):):31-35.

26. Borjian Brojeni S, Mortezaei S, Borjian Brojeni M, Validi M: Study antibacterial effects of hydroalcoholic extract of acorn fruit' s (Quercus branti) against Listeria monocytogenes and Enterococcus faecalis in vitro. Journal of Shahrekord University of Medical Sciences 2016, 17(6):98-106.

27. Omidi A SA: Study Inhibitory activity of some Iranian plant extracts on growth and biofilm formation by Pseudomonas aeruginosa. Armaghane danesh J 2016; 10((21):):117.

28. Khan SU, Khan A-u, Shah A-u-HA, Shah SM, Hussain S, Ayaz M, Ayaz S: Heavy metals content, phytochemical composition, antimicrobial and insecticidal evaluation of Elaeagnus angustifolia. Toxicology and industrial health 2016, 32(1):154-161. 
29. Jamehdor S, Zarabi M, Mehrnejad F: In vitro Evaluation of antibacterial efficacy of aqueous extracts of Iranian Native Plants on the Standard Strains of Pseudomonas aeruginosa. Iranian Journal of Medical Microbiology 2014, 8(2):51-54.

30. Ateufack G, Nana Yousseu W, Dongmo Feudjio B, Fonkeng Sama L, Kuiate J, Kamanyi A: Antidiarrheal and in vitro antibacterial activities of leaves extracts of hibiscus asper. hook. f.(malvaceae). Asian J Pharm Clin Res 2014, 7:130-136.

31. Azaz D, Demirci F, Satıl F, Kürkçüoğlu M, Hüsnü K, Bașerb C: Antimicrobial activity of some Satureja essential oils. Zeitschrift für Naturforschung C2002, 57(9-10):817-821.

32. Mahboubi M, Kazempour N: Chemical composition and antimicrobial activity of Satureja hortensis and Trachyspermum copticum essential oil. Iranian journal of microbiology 2011, 3(4):194.

33. Teimori M: ESSENTIAL OIL ANALYSIS AND ANTIBACTERIAL ACTIVITY OF SATUREJA BACHTIARICA BUNGE. IN ARDEBILE PROVINCE. 2009.

34. Özkalp B, Özcan MM: Antibacterial activity of several concentrations of sater (Satureja hortensis L.) essential oil on spoilage and pathogenic food-related microorganisms. World Applied Sciences Journal 2009, 6(4):509-514. 